\title{
artigo
}

Pereira da Silva, F.; Oliveira, F.P.; Suassuna, L.A.S.; Menezes, M.L.; Lima, R.G.B.; Souto Silva, C.C.;

Riscos e vulnerabilidades dos trabalhadores motociclistas durante a pandemia da COVID-19 no Brasil

\section{Riscos e vulnerabilidades dos trabalhadores motociclistas durante a pandemia da COVID-19 no Brasil}

\author{
Risks and vulnerabilities of motorcyclist workers during the COVID -19 pandemic in Brasil \\ Riesgos y vulnerabilidades de los trabajadores motociclistas durante la pandemia del COVID-19 en Brasil
}

\begin{abstract}
RESUMO
Objetivo: destacar os riscos e vulnerabilidades aos quais os motoboys estão submetidos em razão da profissão, no período da pandemia da COVID-19. Metódo: artigo de revisão de literatura circustanciado pela reflexão mediante análise de artigos científicos presentes na SciELO e PubMed, legislações e boletins epidemiológicos do Ministério da Saúde do Brasil entre maio/junho de 2020. Resultado: cerca de 17 milhões de trabalhadores motoboys possuem renda advinda dos aplicativos de entrega rápida. Esse tipo de trabalho caracteriza-se cada vez mais como alternativa para o desemprego em um mercado exigente, razão pela qual ocorre a desvalorização desta atividade. No contexto da COVID-19, o serviço de delivery cresceu exponencialmente, tornando indispensável o trabalho dos motociclistas frente aos riscos de contaminação pela crescente pandemia. Conclusão: a precarização das condições de trabalho e a terceirização do ofício dos motoboys se agravaram significativamente no atual contexto, juntamente com os riscos de transmissão e contaminação pela COVID-19.
\end{abstract}

DESCRITORES: Riscos ocupacionais; Infecções por Coronavirus; Saúde do Trabalhador.

\section{ABSTRACT}

Objective: to highlight the risks and vulnerabilities on which motorcycle workers are subject to, owing to their profession, during the COVID-19 pandemic period. Method: circumstance-based literature review article throughout reflection based on analysis of scientific articles present at SciELO and PubMed, legislation, and epidemiologic bulletins by the Brazilian Ministry of Health between May/June 2020. Result: approximately 17 million motorcycle restaurant food delivery workers have through fast-delivery applications a source of income. This type of labor is increasingly being characterized as an alternative to unemployment within a demanding market, being so, the reason upon which this certain function is depreciated. Throughout the COVID-19 context, the delivery service has exponentially grown, being the motorcyclist function indispensable among risks imposed by the growing pandemic. Conclusion: the working conditions precariousness and the outsourcing of motorcycle restaurant food delivery workers have significantly worsened in the actual context, together with the transmission and contamination risks by COVID-19.

DESCRIPTORS: Occupational Risks; Coronavirus Infections; Occupational Health.

\section{RESUMEN}

Objetivos: resaltar los riesgos y vulnerabilidades a los que están sujetos los mensajeros en motocicleta debido a su profesión, durante el período de la pandemia del COVID-19. Metódo: artículo de revisión de literature sustentado en la reflexión mediante el análisis de artículos científicos presente en SciELO y PubMed, normativos y boletines epidemiológicos del Ministerio de Salud de Brasil entre Mayo/Junio de 2020. Resultados: alrededor de 17 millones de trabajadores de mensajería en motocicleta obtienen ingresos de las aplicaciones de entrega rápida. Este tipo de trabajo se caracteriza cada vez más como una alternativa al desempleo en un mercado exigente, por lo que esta actividad se devalúa. En el contexto del COVID-19, el servicio de entrega creció exponencialmente, haciendo indispensable el trabajo de los motociclistas ante los riesgos de contaminación por la creciente pandemia. Conclusíon: las precarias condiciones laborales y la subcontratación del trabajo de los mensajeros en motocicleta se han agravado significativamente en el contexto actual, junto con los riesgos de transmisión y contaminación por COVID-19. DESCRIPTORES: Riesgos laborales; Infecciones por coronavirus; Salud del trabajador.

RECEBIDO EM: 19/11/2020 APROVADO EM: 03/12/2020

\section{Fernanda Pereira da Silva}

Acadêmica do curso de Medicina. Faculdade de Medicina Nova Esperança.

ORCID: 0000-0001-5632-1506 


\section{Filipe Pinto de Oliveira}

Acadêmico-- do curso de Medicina. Faculdade de Medicina Nova Esperança.

ORCID: 0000-0002-4795-1917

\section{Letícia Amaral Shizue Suassuna}

Acadêmica do curso de Medicina. Faculdade de Medicina Nova Esperança.

ORCID: 0000-0001-5578-8761

\section{Marília Leite de Menezes}

Acadêmica do curso de Medicina. Faculdade de Medicina Nova Esperança. ORCID: 0000-0003-4550-4061

\section{Roberta Guerra de Brito Oliveira Lima}

Acadêmica do curso de Medicina. Faculdade de Medicina Nova Esperança. ORCID: 0000-0002-8204-7755

\section{Cleyton Cézar Souto Silva}

Professor/Orientador. Doutor em Enfermagem na Atenção a Saúde. Mestrado Profissional em Saúde da Família. Faculdade de Enfermagem e Medicina Nova Esperança.

ORCID: 0000-0002-6187-0187

\section{INTRODUÇÃO}

A sociedade atual se caracteriza pela urgência, instantaneidade e velocidade. Dessa maneira, com o processo de mundialização do capital, a compressão do espaço-tempo ocorreu bruscamente, demandando o surgimento de novas profissões, e extinguindo outras. Assim surgiram os profissionais motociclistas de entrega rápida, conhecidamente chamados como 'motoboys'. Apesar de serem atuantes há mais de 30 anos, sua profissão foi regulamentada apenas no ano de 2009, e tão logo foi vítima do processo de precarização, trazidas pela nova divisão internacional do trabalho e quarta revolução industrial ${ }^{1}$.

Com revolução dos meios de trabalho comandados pela tecnologia da informação, surgiu o conceito das "startups", empresas que iniciam pequenas, com oferta de serviços que ligam virtualmente o produtor ao consumidor, porém, sem nenhuma garantia de vínculo empregatício ou benefícios para os trabalhadores que atuam nessa intermediação. Com essa nova conjuntura, os trabalhadores motoboys se encontram em um trabalho que representa apenas parte da sua renda total, sendo visto como uma renda "extra" e que pode trazer outros benefícios e acúmulos para o desenvolvimento pessoal ${ }^{2}$.
Nesse contexto, o motorista deve entrar com a força de trabalho, e também com os meios de produção, como o veículo necessário para começar a trabalhar, as despesas de internet para celular, combustível, reparos, impostos e seguros, além de assumir a responsabilidade por danos causados a terceiros. Em contrapartida, quase metade dos seus ganhos são retidos pelos aplicativos em que trabalham, os obrigando a dobrar a jornada de trabalho necessária para produzir os ganhos que almejam ${ }^{3}$.

O Sars-CoV-2, vírus causador da covid-19, foi primeiramente identificado em dezembro de 2019, na cidade de Wuhan na China, sendo transmitido pela troca de aerossóis, como a saliva, por meio de contato físico entre pessoas ou contato entre superfícies e objetos contaminados. Por se expressar, em maior parte, de maneira pré-sintómatica ou sintomática, essa doença mostrou possuir uma capacidade contagiosa elevada, atingindo rapidamente muitos países, fazendo que a Organização Mundial da Saúde (OMS), em março de 2020, decretasse o estado de pandemia, que segue em curso até o momento. No Brasil, o primeiro caso foi confirmado em 25 de fevereiro de 2020 , atualmente possuindo mais de $1,5 \mathrm{mi}-$ lhão de casos confirmados com $60 \mathrm{mil}$ óbitos, ultrapassando os números chineses. Os infectadas podem manifestar sintomas variados, desde uma síndrome gripal leve a uma forte dispneia, diarreia e repercussóes cardiovasculares ${ }^{4}$.

Diante desse contexto, os problemas do processo de precarização do trabalho dos entregadores motoboys acentuam ainda mais com a pandemia da COVID-19, que tem se disseminado rapidamente em todo o país. Priorizando a atenção para a saúde pública, os protocolos no Brasil estão pautados em recomendações de medidas sanitárias individuais, através da higiene das mãos com água e sabão ou álcool a $70 \%$, higienização do local de trabalho com detergentes ou água sanitária e a utilização de equipamentos de proteção fundamentais contra a contaminação biológica, a exemplo de máscaras e luvas. Contudo, as medidas de apoio das startups aos motociclistas se mostrou deficitária, e medidas básicas de proteção aos trabalhadores vêm sendo conquistadas apenas depois de muita pressão social, protagonizada, especialmente pelos sindicatos e trabalhadores ${ }^{2}$.

A partir dessa problemática, este artigo de revisão possui o objetivo de identificar os riscos e agravos à sua saúde dos profissionais motoboys no contexto da pandemia do covid-19, além de expor quais vulnerabilidades esses trabalhadores estão expostos durante sua jornada de trabalho. 


\section{METÓDO}

A presente reflexão foi construída circustanciado por revisão de literatura, cujos artigos científicos estavam disponíveis em nas bases de dados Scientific Eletronic Library Online (SciELO) e Public Medline (PubMed). Além disso foram analisadas legislações, relatórios da Organização Pan-Americana de Saúde, boletins epidemiológicos e legislações do Ministério da Saúde do Brasil (MS) referente ao tema COVID-19.

As revisões narrativaa da literatura são importantes para ciência pois descrevem, discutem e refletem criticamente sobre um determinado tema sob um ponto de vista teórico fundamentada na leitura, análise e interpretação dos referenciais bibliográficos disponíveis'.

Com a finalidade de nortear o estudo, formulou-se a seguinte questão de pesquisa: quais os riscos e vulnerabilidades os trabalhadores motociclistas estão expostos neste período de pandemia pelo COVID-19?

A coleta de dados foi realizada entre maio e junho de 2020, sendo a busca dos artigos realizada de forma não controlada, através de descritores do Medical Subject Headings (MESH) Occupational Risks, Coronavirus Infections e Motorcycles cruzados através do operador booleano "AND".

Foram incluídos artigos originais disponíveis na íntegra, gratuitamente nas bases de dados selecionadas e que abordassem a temática proposta, artigos publicados em 2020, nos idiomas inglês, português e espanhol, e que tivessem relacionados com tema riscos e vulnerabilidade dos trabalhadores de delivery. Foram excluídos os artigos em formato de editorial, de carta ao editor ou opinião de especialistas.

Os artigos foram analisados mediante leitura minuciosa por meio dos títulos e análise dos resumos e textos completos. Foram encontrados um total de 30 artigos, sendo escolhidos 15, após processo de seleção com critérios de inclusão e exclusão propostos. Nos textos, foi feita análise do título e resumo a fim de verificar aqueles que estavam de acordo com a temática do estudo. Dos artigos selecionados após análise dos resumos, 08 se enquadravam nos critérios propostos e foram efetivamente lidos por completo e construídas as reflexões. Além disso, foram incluídas na amostra um relatório da Organização Pan-Americana da Saúde, um boletim epidemiológico da Agência Brasil e legislações do MS sobre as medidas para enfrentamento do novo coronavírus.

\section{RESULTADOS}

Os resultados das buscam nas bases de dados resultaram, inicialmente, em 30 trabalhos científicos e após analise dos critérios de elegibilidade restaram 15 artigos, os quais foram lidos o título e o resumo, e apenas 08 artigos foram escolhidos para leitura na integra, fazendo parte da construção desta reflexão juntamente com as legislações do MS vigentes para o período de emergência de saúde pública de importância internacional e demais publicações. Assim foram estabelecidos os seguintes tópicos para discussão: a precarização das condições de trabalho e alienação do motoboy; riscos e agravos à saúde do motoboy; o trabalho dos motoboys no contexto da pandemia.

\section{DISCUSSÃO}

\section{A precarização das condições de tra- balho e a alienação do motoboy}

Atualmente, cerca de 3,8 a 17 milhões de pessoas utilizam aplicativos de celulares como fonte de renda, sendo estas em suma motoboys, que necessitam repassar 20 a $30 \%$ do valor das entregas às plataformas digitais. Estima-se que a média salarial de um motoboy seja de 4 mil reais mensais por mais de 12 horas diárias trabalhadas. Entretanto, este trabalho representa apenas uma parte da renda total do trabalhador, dessa forma, qualquer dia e hora são necessárias para realização do trabalho de entrega ${ }^{2}$.

A precarização do trabalho do motoboy ocorreu a partir do momento em que o movimento do capital exigiu que o processo de produção fosse mais ágil, reforçando a mais-valia e a acumulação por meio do processo de trabalho. Dessa forma, surgiram três tipos de vínculos desses trabalhadores: o precário (contrato terceirizado ou subcontratado), o formal (carteira assinada) e o autônomo (informal) ${ }^{6}$.

Este tipo de contexto de precariedade no trabalho surgiu na era pós-fordista, na qual existe a falta de direitos trabalhistas, carga horária extenuante e extrema dificuldade de ascender socialmente e economicamente, devido a falta de tempo e de oportunidade. Assim, a crise econômica constitui um importante peso decisório para essa realidade dos motoboys, pois o fato de se trabalhar como motociclista profissional se deve a uma solução para o desemprego, em um mercado cada vez mais excludente com a população masculina e jovem, sendo essa uma das justificativas para contribuir na desvalorização junto a este tipo de trabalho ${ }^{7}$.

Ademais, existe uma alienação no processo de trabalho dos motoboys, devido ao fato de que eles possuem uma falsa ideia de liberdade, entendendo as jornadas de trabalho por decisão puramente individual, sendo que na maioria das vezes, não há outra alternativa para suprir suas necessidades básicas e de sua família. Nesse contexto, os motoboys não se sentem empregados das startups, as quais organizam seu processo de trabalho e são proprietárias dos aplicativos que gerenciam as ofertas e as demandas de seus empregos, criando uma falsa visão de racionalização, empreendedorismo e disciplina dos motociclistas, bem quista pelos seus contratantes.

\section{Riscos e agravos à saúde dos motoboys}

Sendo uma das profissões com maior risco de acidentes no trânsito, os motoboys corriqueiramente arriscam-se a fim de abreviar a espera do destinatário e buscando o aumento da produtividade. Todavia, neste processo de trabalho é preciso muitas vezes pôr em xeque a própria vida, expondo-se a diversos riscos para cumprir horários e metas de entregas, seguindo a lógica do just in time ${ }^{8}$.

Segundo a OMS, mais de 1,35 milhões de pessoas morrem no mundo por ano em acidentes de trânsito, em sua maioria, jo- 
vens. Entre essas fatalidades observamos que os motoboys fazem parte de até $28 \%$ delas9. O trânsito no Brasil matou em 2016 mais de 37 mil pessoas em decorrência do trânsito, segundo pesquisa do Ministério da Saúde. Desde 2009, o país tornou-se o quinto no ranking mundial de acidentes de trânsito fatais por motocicletas ${ }^{10}$.

No processo de trabalho dos motoboys, observa-se que uma parcela dos trabalhadores oferecem uma mão de obra de baixo valor social, mas extremamente necessária, proporcionando as classes dominantes a agilidade e a rapidez que a sociedade moderna exige. Durante as corridas, esses motociclistas colocam em risco sua integridade física devido às impossibilidades de execução do tempo de entrega aceitável, resultando ainda na exposição destes ao assédio moral com agressões verbais, violência no trânsito e acidentes ${ }^{11}$.

Vale salientar que na disputa no trânsito entre motoristas de automóveis e motociclistas, haverá sempre um dano material para o motorista do carro, no entanto, para o motoqueiro o dano é além do material, é também físico, podendo chegar a ser fatal. A subnotificação desses acidentes de trabalho aparece como um grave entrave observado na dinâmica laboral dos motoboys, que lidam ainda com a carga física extenuante e os horários de trabalho sem pausas definidas para alimentação.

A ausência de fiscalização das condições de trabalho e dos serviços realizados pelos motoboys impede a visualização da real dimensão dos problemas enfrentados, dificultando assim o acesso às ações da vigilância da saúde do trabalhador. Vários argumentos são usados como pretexto para justificar a carga excessiva imposta durante o processo de trabalho desses motociclistas, como a correlação entre o uso do corpo e da atividade nas ruas como fator positivo da ocupação, sendo essa uma medida contra o sedentarismo ${ }^{8}$.

Por fim, o excesso de carga horária no trabalho é um importante fator a ser identificado, visto que, pode interferir na nutrição desses trabalhadores devido a falta de horários fixos reservados à sua alimentação, uma vez que, os períodos de refeição são a parcela de tempo mais requisitada para entrega. Nesse processo de terceirização precária, é o trabalhador quem agora entra com os meios de produção, arcando com os custos e riscos da atividade, perdendo as garantias e proteções ${ }^{3}$.

\section{A grande demanda}

pelos serviços

de entrega na

conjuntura atual,

colocou os

motoboys na

\section{linha de frente}

\section{da pandemia}

\section{0 trabalho dos motoboys no contex- to da pandemia do Covid-19}

Seguindo as orientações da OMS e as medidas de enfrentamento dispostas pela Portaria $n^{\circ} 356$, de 11 de março de 2020 , baseada na Lei $\mathrm{n}^{\circ} 13.979$, de 06 de fevereiro de 2020, os governos federal, estaduais e municiapais têm executado políticas públicas de incentivo ao isolamento social e a manutenção apenas dos serviços essenciais no contexto da pandemia do novo coronavírus como uma das medidas para "achatar" a curva de contágio e transmissão da doença ${ }^{12}$. Dessa forma, o serviço de entrega em domicílio cresceu de forma exponencial, configurando os motoboys e entregadores delivery como trabalhadores indispensáveis para que as pessoas continuem respeitando as medidas de distanciamento social.

No entanto, apesar de todas as regras sanitárias existentes, não há como garantir de forma adequada que motociclistas responsáveis pela entrega de alimento ou medicamentos, e as empresas de aplicativos responsáveis por este serviço, estejam tomando as efetivas precauções para evitar a transmissão e o contágio pelo novo coronavírus. Dessa forma, esses trabalhadores tornaram-se uma das profissões mais expostas à contaminação pelo vírus, visto que circulam no ambiente externo e entram em contato com muitas pessoas, podendo ser fonte de disseminação e transmissão pelo não uso de Equipamentos de Proteção Individual (EPIs) adequados e de medidas como lavagem das mãos e uso do álcool a 70\%. Sendo assim, pode haver um aumento considerável nos números de casos de COVID-19, inclusive pela contaminação de familiares do trabalhador.

A grande demanda pelos serviços de entrega na conjuntura atual, colocou os motoboys na linha de frente da pandemia, acarretando um aumento da jornada de trabalho e dos riscos ocupacionais desses profissionais, mas não aumentou necessariamente a renda salarial que recebem. Muitos trabalhadores encontram-se por hora desprotegidos, uma vez que as startups em que prestam serviço não têm responsabilidade em oferecer EPIs, como máscaras e luvas, ou até mesmo meios de higienização com álcool em gel ou locais de apoio para lavagem das mãos. Isso se deve ao fato de a maioria desses trabalhadores serem microempreendedores individuais e não possuírem vínculos empregatícios com essas empresas, o que dificulta a fiscalização e cobrança ao acesso aos meios de prevenção que assegurem a sua saúde.

Tanto o exercício das atividades laborais quanto às condições de trabalho se mostram como fontes potenciais de exposição e de disseminação do vírus, por isso, a análise da maneira como as atividades de trabalho se processam é determinante para a prevenção do adoecimento ${ }^{13}$. Tendo isso em consideração, é importante que se tenha um olhar diferenciado para o processo de trabalho dos motoboys e que as autoridades públicas de orgão como Ministério de Trabalho e Emprego e Ministério Público consigam efetivamente proteger a saúde desses trabalhadores tão essenciais nesse momento de reclusão domiciliar. 


\section{artigo}

Pereira da Silva, F.; Oliveira, F.P.; Suassuna, L.A.S.; Menezes, M.L.; Lima, R.G.B.; Souto Silva, C.C.

Riscos e vulnerabilidades dos trabalhadores motociclistas durante a pandemia da COVID-19 no Brasil

Além disso, as empresas de aplicativos devem desempenhar o papel de cidadãs no combate a pandemia, não visando aumentar os lucros sem proteger seus trabalhadores, oferecendo orientações acerca da importância das medidas preventivas como deixar encomendas nas portas, manter 2 metros de distância do cliente, preferir pagamento em débito online ao dinheiro, uso de máscaras e luvas, higienização das mãos com álcool em gel, e no menor sinal de sintomas afastar o trabalhador e encaminhá-lo à assistência médica.

Em razão de acentuado aumento na precarização das condições de trabalho, os moto- boys realizaram $\mathrm{em} 1^{\circ}$ de julho de 2020 uma paralização em várias cidades do país para exigir melhores condições. Dentre as exigências, o grupo cobra das empresas uma ajuda de custo para a aquisição de equipamentos de proteção contra a COVID-19, como máscaras e luvas, pede maior transparência sobre as formas de pagamento adotadas pelas plataformas, aumento dos valores mínimos para cada entrega, mais segurança e fim dos sistemas de pontuação, bloqueios e "exclusões indevidas".

\section{CONCLUSÕES}

Pode-se concluir que as condições de trabalho cujos trabalhadores motoboys estão submetidos são, em grande parte, precárias e ainda deficitárias de políticas que de fato assegurem a saúde física e psicológica dessa categoria de trabalho. Por meio do presente ensaio entendeu-se que os agravos e riscos do processo de trabalho aos quais esses trabalhadores se expõem, constituem um forte entrave para garantia de direitos básicos como saúde, segurança e renda digna. Ademais, é perceptível que o atual contexto de pandemia reforça ainda mais toda essa conjuntura de precarização e terceirização. "

\section{REFERÊNCIAS}

1. Godoi SC. Sofrimento e trabalho na cidade em marcha forçada. Cad. Metrop. 2016, 18 (36): 345-363. Disponível em: $\quad$ https://www.scielo.br/scielo.php?script=sci_arttext\&pid=S2236-99962016000200345\&Ing=en\&nrm=iso\&tlng=pt. Acesso em 30 de maio de 2020.

2. Machado L. Dormir na rua e pedalar 12 horas por dia: a rotina dos entregadores de aplicativos. BBC News Brasil [internet] 22 maio 2019 [citado 29 Maio 2020]. Disponível em: https://www. bbc.com/portuguese/brasil-48304340.

3. Abilio LC. Uberização: a era do trabalhador just-intime? Estud. av. 2020, 34 (98):111-126. Disponivel em: $\quad$ http://www.scielo.br/scielo.php?script=sci_arttext\&pid=S0103-40142020000100111\&lng=en\&nrm=iso Acesso em 30 de Maio 2020.

4. Dantas C, Oliveira E, Manzano F, Valadares M. Coronavírus: COVID-19 o que se sabe [internet] 27 abr. 2020 [citado em 29 Maio 2020]. Disponível em: https://especiais.g1.globo.com/bemestar/2020/coronavirus/? _ ga $=2.169161641 .98796139 .1590864806-C 815 F D 08-B B 12-$ 4A79-8E6E-FE5BA411B8EB.

5. Rother ET. Revisão sistemática x revisão narrativa. Acta Paul Enferm [Internet]. 2007 [acesso em 2020 mar 30]; 20(2): 0102. Disponivel em: https://www.scielo.br/scielo.php?script=sci_art-text\&pid=S0103-21002007000200001.

6. Castro MF. Os motoboys de São Paulo e a produção de táticas e estratégias na realização das práticas cotidianas [Doutorado]. São Paulo: Instituto de Psicologia da Universidade de São Paulo, 2010. Disponivel em: https://www.teses.usp.br/teses/disponiveis/47/47134/tde-09022011-111013/pt-br.php

7. Silva DW, Andrade SM, Soares DA, Nunes EFPA, Melchior R. Condições de trabalho e riscos no trânsito urbano na ótica de trabalhadores motociclistas. Physis 2008, 18 (2): 339-360. Disponivel em: <http://www.scielo.br/scielo.php?script=sci_arttext\&pid=S0103-73312008000200008\&Ing=en\&nrm=iso $>$. Acesso em 30 Maio 2020.
8. Weiss HC. O céu é o limite:: trabalho uberizado e governamentalidade neoliberal nos entregadores-ciclistas em Porto Alegre [Monografia]. Porto Alegre: Universidade Federal do Rio Grande do Sul, 2019. Disponivel em: http://hdl.handle. net/10183/206588. Acesso em: 28 maio 2020.

9. Organização Pan-Americana da Saúde. Relatório da Organização Mundia de Saúde destaca progressos insuficientes para enfrentar falta de segurança nas vias do mundo [internet] 7 dez. 2018 [citado em 30 Julho 2020]. Disponivel em: <https:// www.paho.org/bra/index.php?option=com_content\&view=article\&id=5818:relatorio-da-oms-destaca-progressos-insuficientes-para-enfrentar-falta-de-seguranca-nas-vias-do-mundo\&ltemid=839>.

10. Vilela PR. Brasil reduz mortes no trânsito, mas está longe da meta para 2020. Agência Brasil [internet] 18 Set. 2020 [citado em 29 Maio 2020]. Disponivel em: http://www.clicrbs.com.br/ zerohora/jsp/default.jspx?uf=1\&action=flip.

11. Scotti F. "Ricardo, voa!": A dor e a delícia de ser motoboy na grande Florianópolis [Monografia]. Florianópolis: Universidade Federal de Santa Catarina, 2019. Disponivel em: https://repositorio.ufsc.br/bitstream/handle/123456789/200497/TCC\%20 -\%20Filipe\%20Scotti.pdf?sequence=1\&isAllowed=y. Acesso em: 29 maio 2020.

12. Brasil. Ministério da Saúde. Gabinete do Ministro. Portaria $n^{\circ}$ 356, de 11 de Março de 2020. Dispõe sobre a regulamentação e operacionalização do disposto na Lei n 13.979, de 6 de fevereiro de 2020, que estabelece as medidas para enfrentamento da emergência de saúde pública de importância internacional decorrente do coronavírus (COVID-19). Disponivel em: http:// www.in.gov.br/en/web/dou/-/portaria-n-356-de-11-de-marco-de-2020-247538346, Acesso em: 30 maio 2020.

13. Fiho JMJ et al. A saúde do trabalhador e o enfrentamento da COVID-19. Rev. Bras. Saúde Ocup. 2020, 45:e14. Disponível em: https://www.scielo.br/pdf/rbso/v45/2317-6369-rbso-45-e14. pdf. Acesso: 29 de maio 2020. 